Den Nachweis von freien Säuren in organischen Flüssigkeiten, zum Beispiel Urin, will F. Repiton ${ }^{1}$ ) mittels Fehling'scher Lösung führen. Letztere soll schon durch geringe Mengen freier Säuren reduziert werden. $\mathrm{Zu}$ diesem Zwecke erhitzt man $5 \mathrm{~cm}$ Fehling'scher Lösung zum Sieden und lässt allmählich die auf die Anwesenheit organischer oder mineralischer Säuren zu prüfende Flüssigkeit tropfenweise auf die Oberfläche fallen. Sind freie Säuren zugegen, so soll sich am Berührungspunkt eine trübe Zone bilden und in der Rube sich ein Kupferoxydulniederschlag absetzen. Auf diese Weise will der Verfasser freie Milchsäure, Ameisensäure, Essigsäure, Zitronensäure und Schwefelsäure nachgewiesen haben. ${ }^{2}$ )

\title{
Einige neue Reaktionen zum Nachweis geringer Mengen Glyzerin
} hat G. Denig ès ${ }^{3}$ ) gefunden. Es handelt sich hierbei um Reaktionen des Dioxyaethans, eines Körpers, der sehr leicht aus Glyzerin erhalten wird. Dioxyaethan gibt nämlich mit Kodeïn, Resorzin, Thymol, $\beta$-Naphtol und Salizylsäure charakteristische Farbenreaktionen, ferner mit Phenylhydrazin, sowie mit dem Nessler'schen Reagens, der Fehling'schen Lösung und ferrocyanidhaltiger Fehling'scher Lösung cliarakteristische Niederschläge. Am empfindlichsten ist der Nachweis mittels Kodeïns oder Salizylsäure. Die Überführung des Glyzerins in Dioxyaethan geschieht durch Erhitzen der zu untersuchenden Lösung mit Bromwasser.

Eine Methode zur Analyse der natürlichen und künstlichen organischen Farbstoffe hat A. G. Rota ${ }^{4}$ ) ausgearbeitet.

Im ersten Teil seiner Arbeit berichtet er uber die Analyse der einzelnen Farbstoffe, während der zweite Teil die Analyse der Farbstoffmischungen behandelt.

Die besten Resultate zur Unterscheidung der einzelnen Farbstoffe ergab ibr Verhalten bei der Reduktion, namentlich gegenüber einer Lösung von Zinnchlorür und Salzsäure bei Anwendung stark verdünnter Lösungen (1:10000) der Farbstoffe. Was die reduzierten Lösungen betrifft, so zeigt es sich, dass einige darunter durch einige Tropfen Eisenchlorid oder durch Schütteln mit Luft, nach Neutralisation mit

1) Annal. Chim. analyt. 18, 269 (1908).

2) Ich habe die mir ganz unwahrscheinlich vorkommende Angabe nachgeprüft. Mit verdünnter Schwefelsüure trat keinerlei Reaktion ein.

3) Bull. de la soc. chim. de Paris [4. Série] 5, 421.

W. Fresenius.

4) Chemiker-Zeitung 22, 437. 